

\section{Take Me Up With You Dearie.}

\section{Patter Chorus.}

For Singer Only.
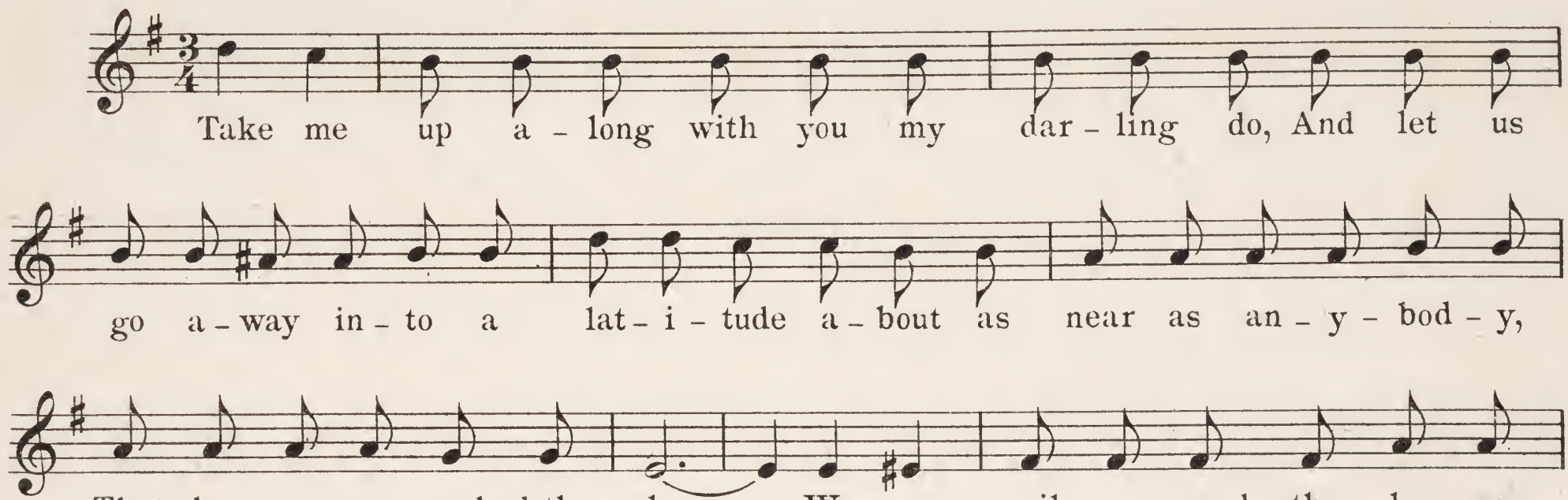

That has ev - er reached the sky, W We can sail a - round the $1 \mathrm{u}$ - nar
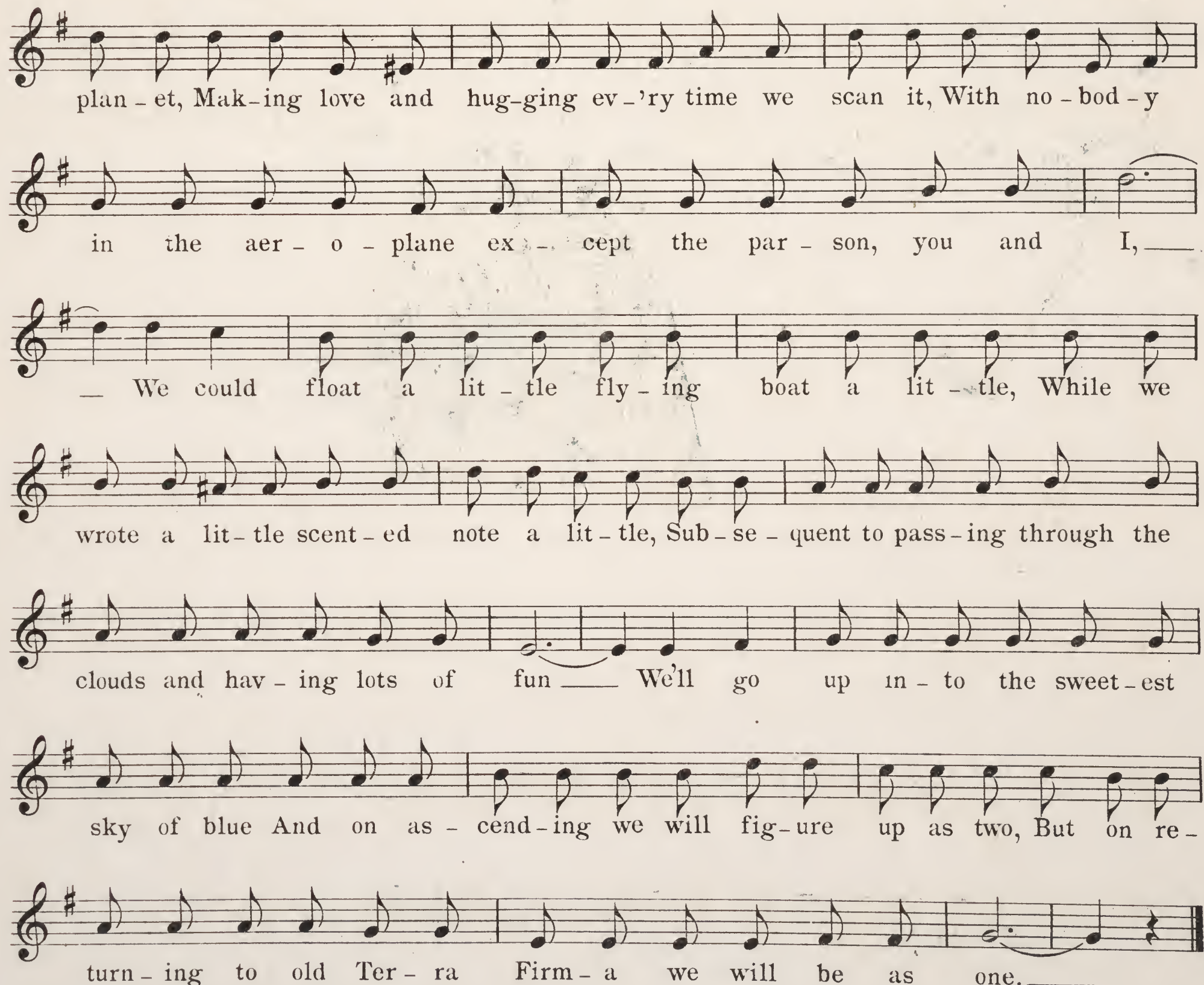

NOTE = Accompaniment to above is same as regular Chorus. 


\section{Take Me Up With You Dearie.}

Words by

JUNIE MC CREE.
Music by

ALBERT VON TILZER.

Tempo di Valse.


All Rights Reserved.

English Performing Rights Reserved.

Copyright MCMIX by The York Music Co.

Albert Von Tilzer Mgr.

1367 Broadway New York. 

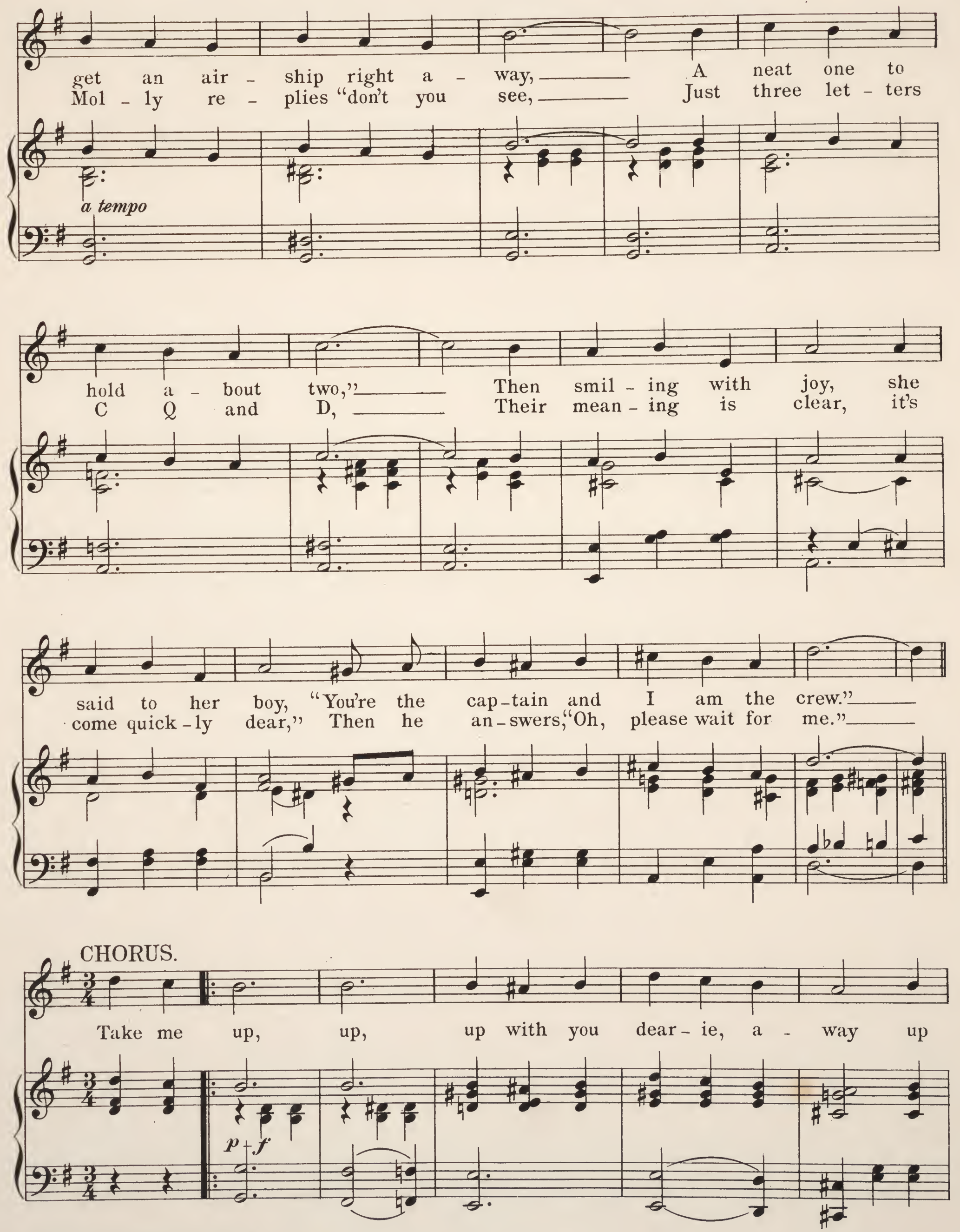

Take me up with you dearie. 3 
强 to the sky,_ Sail a - round the moon for a qui - et spoon Just the
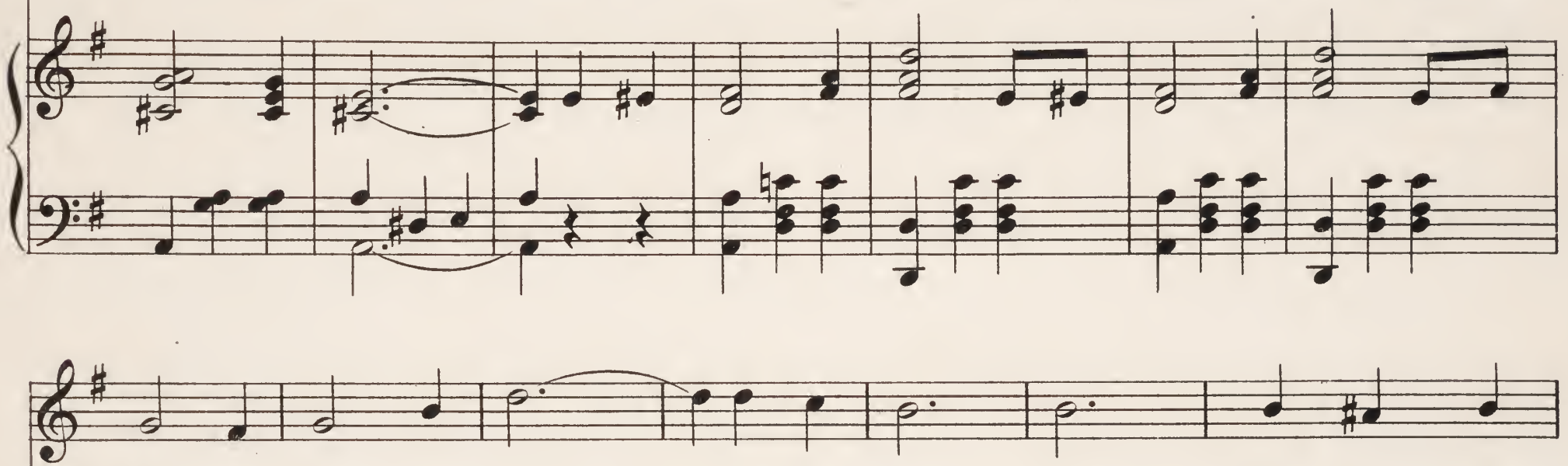
par-son you and I,_Let us float, float, float through the
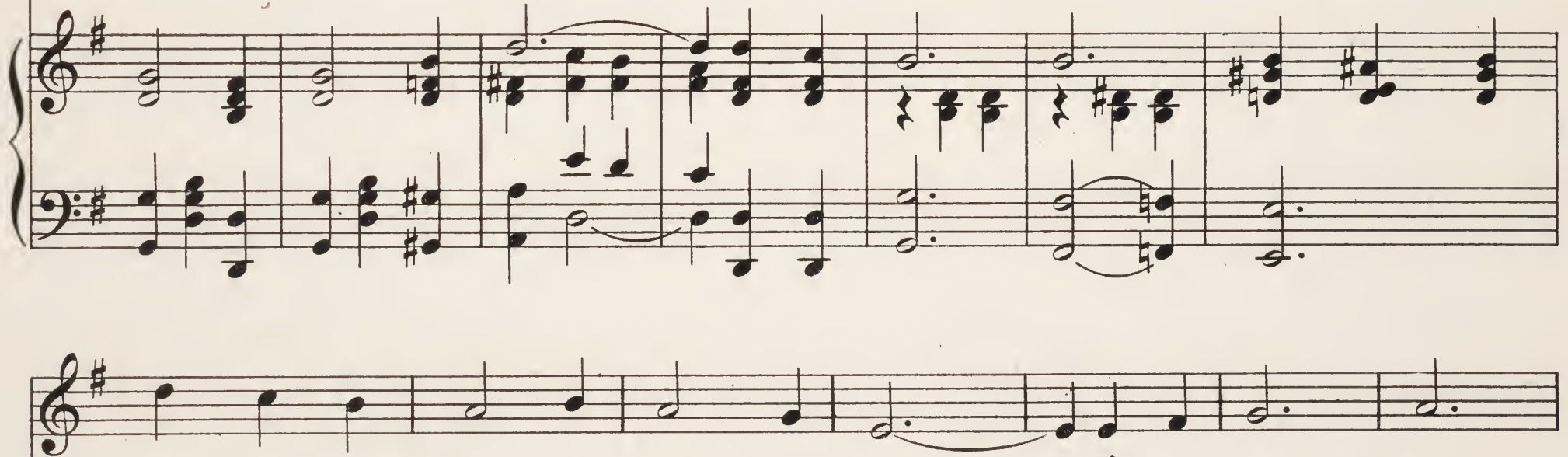
clouds and just have a lot of fun_ We'll go up, up,
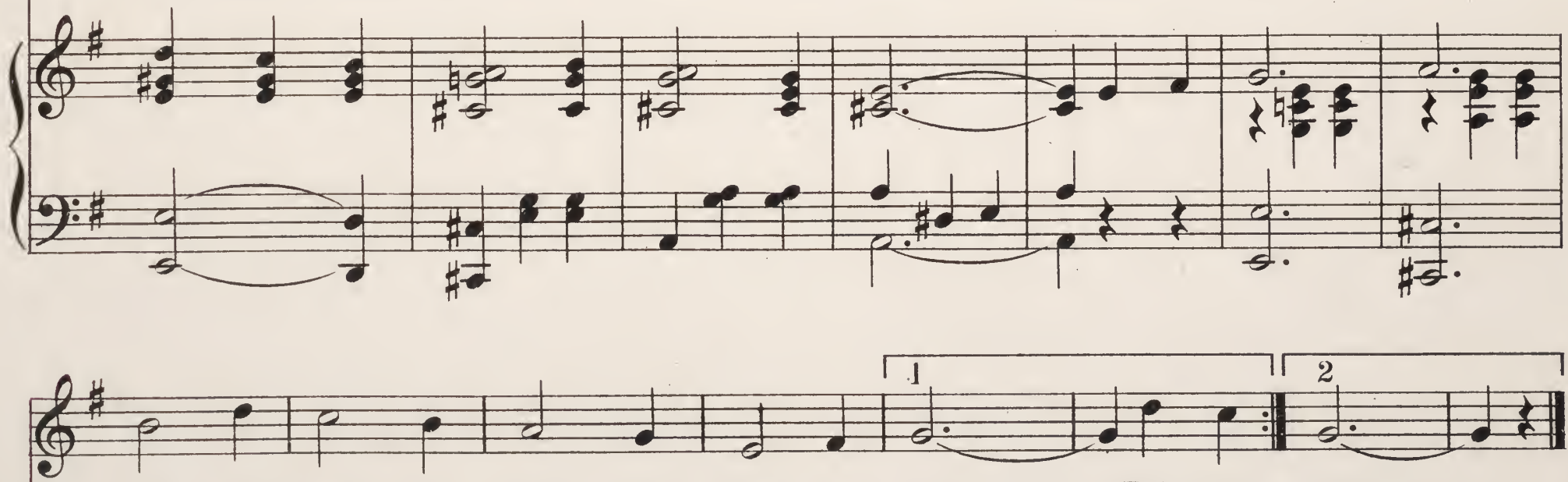
up as two and then come down as one._ Take me one.

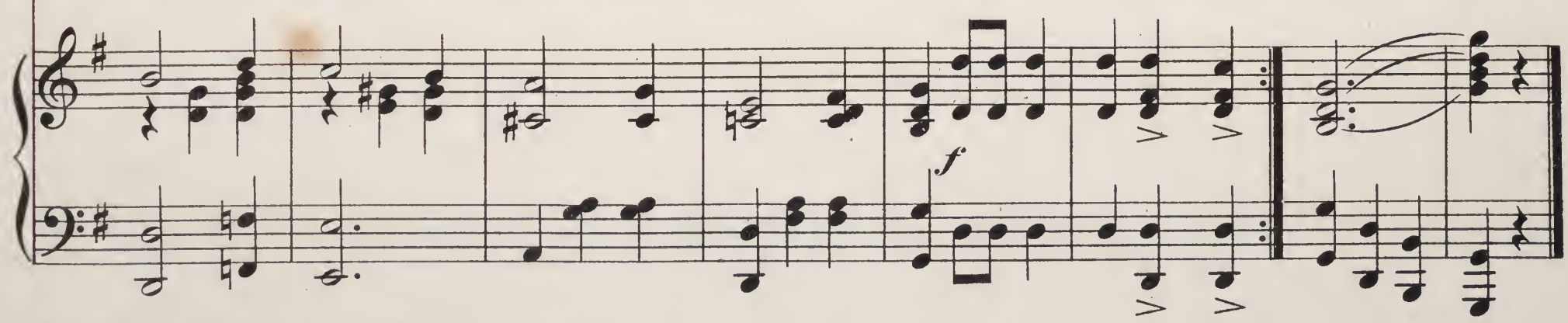

Take me up with you dearie 3 


\section{SONGS THAT SHOULD BE IN EVERY HOME}
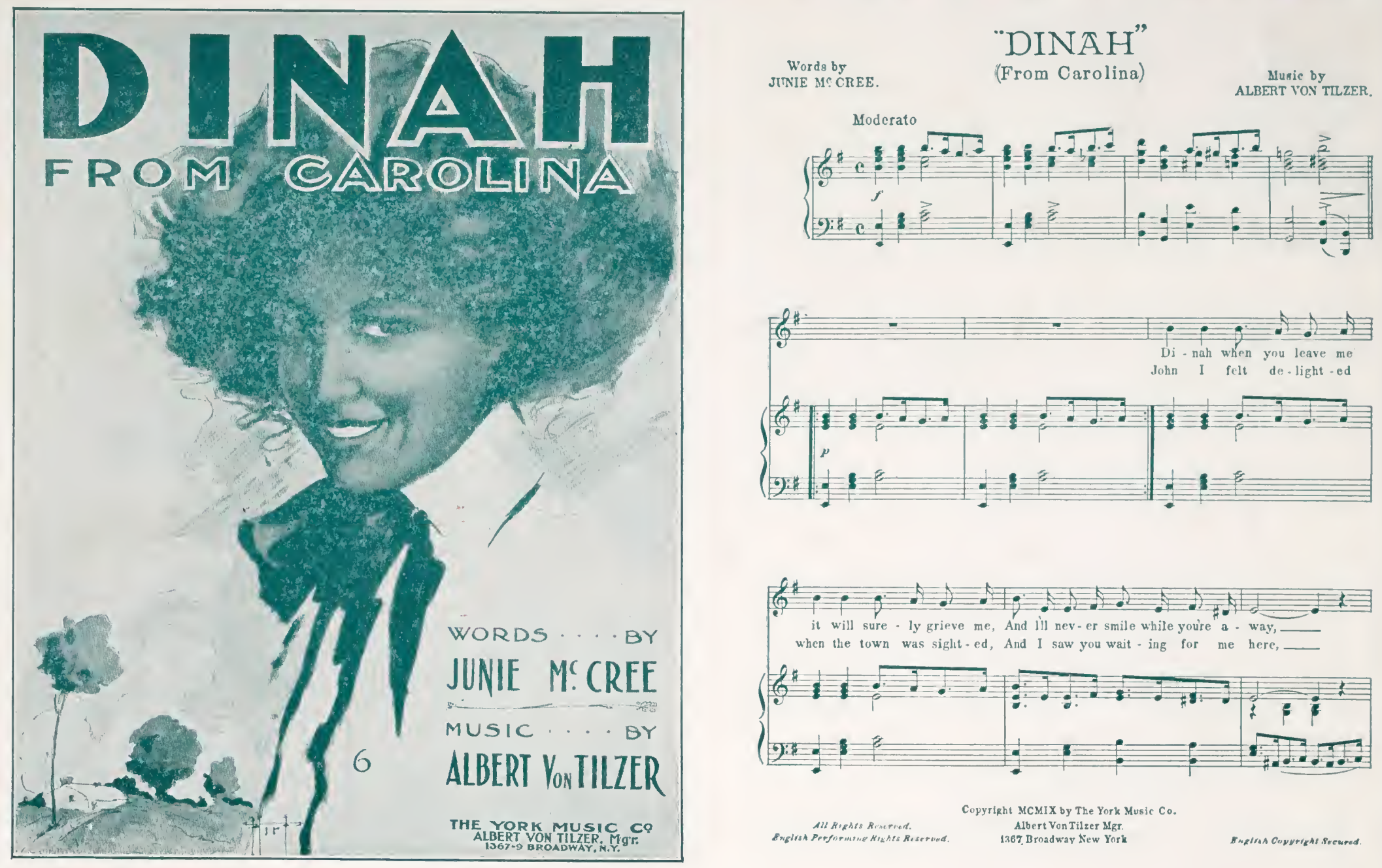

This Song is more popular than "Carrie Marry Harry"

NORA MALONE

Words by
JUNIE Me CREE. (Call Me By'Phone)

(f)

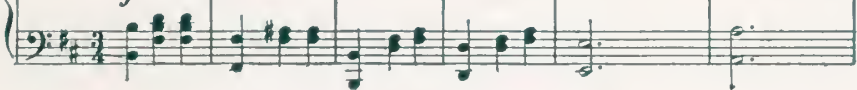

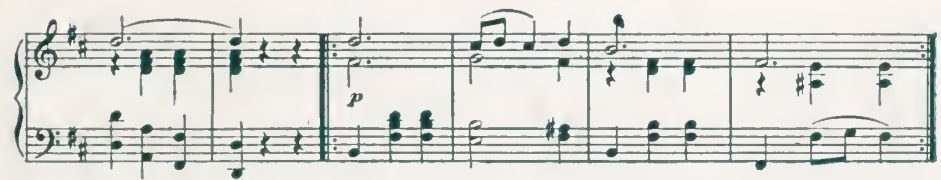

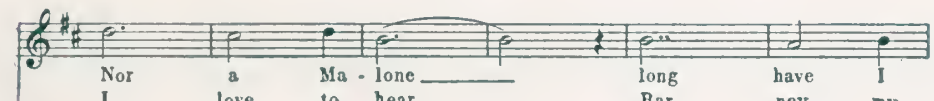

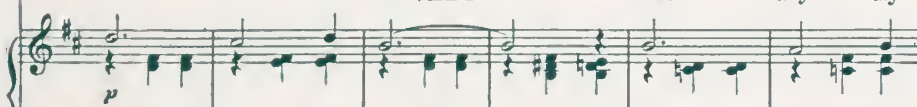



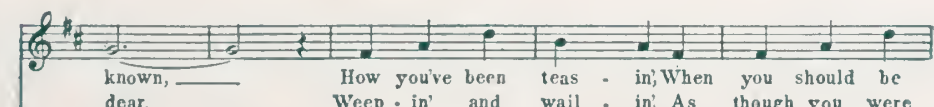

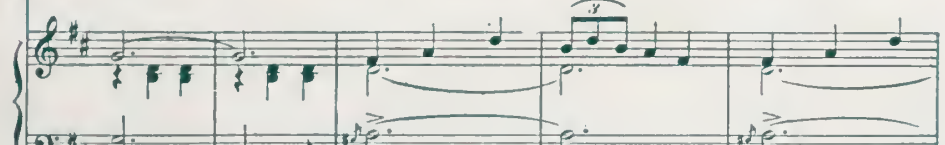

2) 2 in:

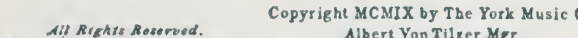

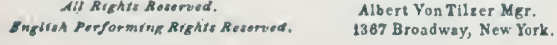



Nora Malone is Blanche Ring's Biggest Hit. The Song Success of New York

Complete copies for sale at all music stores or, if your dealer cannot supply you, we will, on receipt of 25 cts. each mail copies anywhere.

THE YORK MUSIC CO., Albert Von Tilzer, Mgr.

1367 Broadway, New York. 